\title{
Glucose-regulated protein 94 mediates progression and metastasis of esophageal squamous cell carcinoma via mitochondrial function and the NF-kB/COX-2/VEGF axis
}

\author{
Chien-Yu Huang ${ }^{1,2, *}$, Chia-Hwa Lee ${ }^{3}$, Chao-Chiang Tu ${ }^{4,5, *}$, Chih-Hsiung Wu ${ }^{1,2,10}$, \\ Ming-Te Huang ${ }^{1,2}$, Po-Li Wei ${ }^{1,6,7,8,9}$ and Yu-Jia Chang ${ }^{4,7}$ \\ ${ }^{1}$ Department of Surgery, College of Medicine, Taipei Medical University, Taipei, Taiwan \\ ${ }^{2}$ Division of General Surgery, Department of Surgery, Shuang Ho Hospital, Taipei Medical University, Taipei, Taiwan \\ ${ }^{3}$ School of Medical Laboratory Science and Biotechnology, College of Medical Science and Technology, Taipei Medical \\ University, Taipei, Taiwan \\ ${ }^{4}$ Graduate Institute of Clinical Medicine, College of Medicine, Taipei Medical University, Taipei, Taiwan \\ ${ }^{5}$ Division of General Surgery, Department of Surgery, Fu Jen Catholic University Hospital; School of Medicine, College of \\ Medicine, Fu-Jen Catholic University, Taipei, Taiwan \\ ${ }^{6}$ Division of Colorectal Surgery, Department of Surgery, Wan Fang Hospital, Taipei Medical University, Taipei, Taiwan \\ ${ }^{7}$ Cancer Research Center and Translational Laboratory, Department of Medical Research, Taipei Medical University Hospital, \\ Taipei Medical University, Taipei, Taiwan \\ ${ }^{8}$ Division of Colorectal Surgery, Department of Surgery, Taipei Medical University Hospital, Taipei Medical University, Taipei, \\ Taiwan \\ ${ }^{9}$ Graduate Institute of Cancer Biology and Drug Discovery, Taipei Medical University, Taipei, Taiwan \\ ${ }^{10}$ En Chu Kong Hospital, Taipei, Taiwan \\ *These authors contributed equally to this work
}

Correspondence to: Yu-Jia Chang, email: r5424012@tmu.edu.tw Po-Li Wei, email: poliwei@tmu.edu.tw

Keywords: ESCC; GRP94; VEGF; COX-2

Received: July 03, $2017 \quad$ Accepted: December 01, $2017 \quad$ Published: January 10, 2018

Copyright: Huang et al. This is an open-access article distributed under the terms of the Creative Commons Attribution License 3.0 (CC BY 3.0), which permits unrestricted use, distribution, and reproduction in any medium, provided the original author and source are credited.

\section{ABSTRACT}

Esophageal cancer is a worldwide health problem with a very poor prognosis. Therefore, new diagnostic biomarkers or therapeutic strategies for identifying and managing esophageal squamous cell carcinoma (ESCC) are urgently needed. Glucoseregulated protein 94 (GRP94) is one of major endoplasmic reticulum-stress response proteins that plays a key role in cancer progression and therapeutic responses. However, the role of GRP94 in ESCC progression and metastasis remains unclear. The tissue array results indicated that higher GRP94 expression levels were associated with lower overall survival and higher lympho-node metastasis. Silencing GRP94 (GRP94-KD) reduced cell proliferation, migration and invasion in ESCC cells. In a xenotransplantation assay, silencing GRP94 reduced cell proliferation in the zebrafish embryo. Transmission electron microscopy revealed impaired mitochondria in GRP94KD cells, which exhibited reduced basal respiration, spare respiratory capacity and ATP production and increased oxidative damage compared with scrambled control cells. Regarding the molecular mechanism underlying the effects of GRP94 knockdown, we found that silencing GRP94 may reduce the level of NF-kB, c-Jun, p38, IL-6, vascular endothelial growth factor (VEGF), and cyclooxygenase-2 (COX-2) as well as activation of AKT and ERK. In conclusion, our results indicate that silencing GRP94 in ESCC cells suppressed cancer growth and the metastatic potential via mitochondrial functions and NF-kB/COX-2/VEGF in ESCC cells. 


\section{INTRODUCTION}

Esophageal cancer is a very aggressive cancer comprising two main histological types, squamous cell carcinoma and adenocarcinoma. In certain countries with a high incidence of esophageal carcinoma such as China, up to $90 \%$ of all esophageal cancer cases are squamous cell carcinomas [1]. The risk factors for esophageal squamous cell carcinoma (ESCC) and esophageal adenocarcinoma are smoking, excessive alcohol intake, high-temperature drinks [2, 3], obesity, and chronic gastroesophageal reflux disease $[4,5]$. The therapeutic outcomes of esophageal cancer are dismal, as most patients present with distant metastasis when first diagnosed. The 5-year survival rate ranges from $10 \%-20 \%$ and increases to $40 \%$ with surgical intervention [6-8]. Most patients with ESCC die within the first year after diagnosis, indicating the importance of early ESCC diagnosis. p53 gene mutations are frequently detected in esophageal cancer [9], and dysregulation of cell regulators, such as epidermal growth factor receptor $[10,11]$, HER-2/Neu [12], and vascular endothelial growth factor [13], has been investigated in ESCC. It is urgent to find an effective biomarker for improving prognostic and therapeutic efficacy in ESCC.

Glucose-related protein 94 (GRP94) is a member of the HSP90 family. GRP94 is an endoplasmic reticulum (ER) chaperone whose main function entails assisting with protein folding, assembly and secretion. GRP94 also helps cells to survive stresses, such as ischemia, starvation, radiation and chemotoxicity [14-17]. In malignant diseases, GRP94 is highly expressed in cancer tissues, and its expression correlates with the therapeutic response [16, 18]. Specifically, increased GRP94 protein expression is associated with poor tumor differentiation, invasiveness and metastasis, radioresistance and chemoresistance in many different cancers $[15,19,20]$. Silencing GRP94 expression promotes apoptosis with or without ER stress $[21,22]$, and blocking GRP94 function may suppress tumorigenesis and metastasis in liver cancer [23-25]. Immunohistochemical staining has demonstrated that there is a significant correlation between GRP94 expression and the progression of esophageal cancer [26-29]. However, the role and regulatory mechanism of GRP94 in ESCC progression is not fully understood.

Vascular endothelial growth factor (VEGF) is a pivotal factor in the complex process of angiogenesis. The VEGF family comprises the following seven members: VEGF-A, VEGF-B, VEGF-C, VEGF-D, VEGF-E, VEGF-F, and PIGF [30]. VEGF expression is reportedly inversely correlated with clinicopathological outcomes in ESCC $[31,32]$.

Our study demonstrated that GRP94 depletion inhibited cancer cell proliferation and metastatic potential by suppressing the AKT and MAPK pathways. In addition, we found that the reduction of IL-6, VEGF and COX-2 levels was due to suppression of NF-kB and AP-1 production after silencing GRP94 in ESCC cells. Therefore, we conclude that GRP94 may be a good therapeutic target for the treatment of ESCC.

\section{RESULTS}

\section{Clinicopathological features of ESCC and GRP94 expression}

To better understand the prognostic role of GRP94 in ESCC, we performed immunohistochemical staining for GRP94 on ESCC tissue microarray sections. The clinicopathological features (HEso-Squ172Sur-02 tissue microarray) of the individuals who provided these samples are presented in Table 1. A total of 91 patients with clinicopathological and GRP94 expression data were evaluated. First, we compared GRP94 expression levels in ESCC tissue samples and matched normal esophageal squamous epithelial tissue samples (Figure 1A). ESCC tissue (GRP94 expression score: mean \pm standard deviation, $201.6 \pm 48.4$ ) exhibited significantly higher GRP94 expression than normal esophageal squamous epithelial tissue (GRP94 expression score: $98.2 \pm 50.0$ ) $(P<0.001)$. The association between clinicopathological characteristics and GRP94 expression is presented in Table 1. Patients in the high GRP94 expression group tended to exhibit a higher frequency of lymph node metastasis than patients in the low GRP94 expression group $(P=0.032)$, and patients with high GRP94 expression levels tended to present at a later disease stage than patients with low GRP94 expression levels, although the difference between these two groups was not significant $(P=0.057)$.

\section{Analysis of the prognostic impact of GRP94 expression on overall survival}

Kaplan-Meier curve analysis demonstrated that overall survival was significantly higher among patients with low GRP94 expression levels than among patients with high GRP94 expression levels $(P=0.005)$ (Figure 1B). Univariate and multivariate analyses were performed using Cox proportional hazards models to identify independent prognostic factors for overall survival (Table 2). Univariate analysis demonstrated that male gender, deeper invasion $(\mathrm{T} 3+\mathrm{T} 4)$, lymph node metastasis, advanced pathologic stages (stages III and IV) and high GRP94 expression levels were associated with poorer prognosis. Multivariate analysis demonstrated that gender, age, and high GRP94 expression levels were independent prognostic factors for overall survival. Similar results were observed using the other tissue microarray (HEso-Squ172Sur-01) (data not shown). 
Table 1: Association between clinicopathological characteristics and GRP94 expression

\begin{tabular}{|c|c|c|c|}
\hline \multirow[t]{2}{*}{ Characteristics } & \multicolumn{2}{|c|}{ GRP94 expression } & \multirow{2}{*}{$P$ value } \\
\hline & Low $(n=52)$ & High $(n=39)$ & \\
\hline Gender & & & 0.770 \\
\hline Male & $40(77 \%)$ & $31(79 \%)$ & \\
\hline Female & $12(23 \%)$ & $8(21 \%)$ & \\
\hline Mean Age (years) $\pm \mathrm{SD}$ & $63.3 \pm 7.9$ & $66.0 \pm 9.2$ & 0.129 \\
\hline Age & & & 0.328 \\
\hline$<65$ years & $32(62 \%)$ & $20(51 \%)$ & \\
\hline$\geq 65$ years & $20(38 \%)$ & $19(49 \%)$ & \\
\hline Grading of SCC & & & 0.327 \\
\hline Well differentiated & $8(15 \%)$ & $6(15 \%)$ & \\
\hline Moderately differentiated & $38(73 \%)$ & $24(62 \%)$ & \\
\hline Poorly differentiated & $6(12 \%)$ & $9(23 \%)$ & \\
\hline Invasive depth of tumor ${ }^{* 1}$ & & & 0.395 \\
\hline $\mathrm{T} 1+\mathrm{T} 2$ & $17(34 \%)$ & $10(26 \%)$ & \\
\hline $\mathrm{T} 3+\mathrm{T} 4$ & $33(66 \%)$ & $29(74 \%)$ & \\
\hline \multicolumn{4}{|l|}{ Lymph node metastasis ${ }^{* 2}$} \\
\hline Negative & $35(70 \%)$ & $18(47 \%)$ & 0.032 \\
\hline Positive & $15(30 \%)$ & $20(53 \%)$ & \\
\hline Stage (AJCC 7th Ed) ${ }^{* 3}$ & & & 0.057 \\
\hline $\mathrm{I}+\mathrm{II}$ & $37(77 \%)$ & $22(58 \%)$ & \\
\hline $\mathrm{III}+\mathrm{IV}$ & $11(23 \%)$ & $16(42 \%)$ & \\
\hline
\end{tabular}

${ }^{{ }^{*} 1}$ Missing data in 2 cases; ${ }^{{ }_{2}}$ missing data in 3 cases; ${ }^{{ }_{3}}$ missing data in 5 cases

Abbreviation: AJCC, American Joint Committee on Cancer

\section{GRP94 expression analysis and manipulation in ESCC cells}

To examine the role of GRP94 in ESCC, we assessed GRP94 expression in the indicated ESCC cell lines. As shown in Figure 2A, KYSE 170, CE81T, and CE146T cells exhibited highly GRP94 expression by western blotting,indicating that GRP94 plays an essential role in ESCC. To elucidate the role of GRP94 in ESCC further, we knocked down GRP94 expression using shRNA and determined the level of GRP94 in GRP94-shRNA transfected (GRP94-KD) CE81T and KYSE 170 cells (Figure 2B). The level of GRP94 was reduced dramatically in GRP94KD CE81T and KYSE 170 cells compared with scrambled control shRNA-transfected (scrambled control) cells.

\section{Silencing GRP94 decreased cell proliferation}

To analyze the biological effects of GRP94 downregulation in ESCC cells, we assessed GRP94-KD and scrambled control CE81T cell growth via MTT assays and a biosensor system. GRP94-KD CE81T cells exhibited a lower growth rate than scrambled control CE81T cells (Figure 2C). Using the xCELLigence biosensor system, we also observed that GRP94-KD cell growth was reduced by more than $50 \%$ compared with scrambled control cell growth (Figure 2D). In the colony formation assay, GRP94-KD cells produced fewer colonies than scrambled control cells (Figure 2E). Overall, these results indicate that suppressing GRP94 expression in ESCC cells diminished their growth activity.

\section{Silencing GRP94 decreased ESCC metastasis and invasiveness}

Many ESCC patients present with stage III disease when first diagnosed with cancer, indicating that understanding the molecular mechanisms underlying ESCC metastasis is important and may facilitate the development of better therapeutic strategies for the treatment of ESCC. We examined the role of GRP94 in ESCC metastasis via transwell migration, wound-healing and invasion assays. As shown in Figure 3A, GRP94KD CE81T cells exhibited less migration than scrambled control cells. In wound-healing migratory assay, silenced GRP94 in KYSE 170 cells caused a reduction of woundhealing ability compared with scrambled control cells (Figure 3B). Similarly, in invasion assays, more invasive cells were present in the scrambled control group than in the GRP94-KD group (Figure 3C and 3D). These results 
Table 2: Univariate and multivariate analyses of clinicopathological factors and GRP94 expression affecting overall survival

\begin{tabular}{|c|c|c|c|}
\hline \multirow[t]{2}{*}{ Variables } & \multicolumn{2}{|c|}{ Overall survival } & \multirow{2}{*}{$P$ value } \\
\hline & Hazard ratio & $95 \%$ CI & \\
\hline \multicolumn{4}{|l|}{ Univariate analysis } \\
\hline \multicolumn{4}{|l|}{ Gender } \\
\hline Male & 1 & - & - \\
\hline Female & 0.334 & $0.119-0940$. & 0.038 \\
\hline \multicolumn{4}{|l|}{ Age } \\
\hline$<65$ years & 1 & - & - \\
\hline$\geq 65$ years & 1.549 & $0.832-2.883$ & 0.167 \\
\hline \multicolumn{4}{|l|}{ Grading of SCC } \\
\hline Well-moderately differentiated & 1 & - & - \\
\hline Poorly differentiated & 1.726 & $0.820-3.630$ & 0.150 \\
\hline \multicolumn{4}{|l|}{ Invasive depth of tumor } \\
\hline $\mathrm{T} 1+\mathrm{T} 2$ & 1 & - & - \\
\hline $\mathrm{T} 3+\mathrm{T} 4$ & 2.439 & $1.076-5.530$ & 0.033 \\
\hline \multicolumn{4}{|l|}{ Lymph node metastasis } \\
\hline Negative & 1 & - & - \\
\hline Positive & 1.895 & $1.002-3.582$ & 0.049 \\
\hline \multicolumn{4}{|l|}{ Stage (AJCC 7th Ed) } \\
\hline $\mathrm{I}+\mathrm{II}$ & 1 & - & - \\
\hline $\mathrm{III}+\mathrm{IV}$ & 2.215 & $1.159-4.250$ & 0.017 \\
\hline \multicolumn{4}{|l|}{ GRP94 expression } \\
\hline Low & 1 & - & - \\
\hline High & 2.480 & $1.276-4.546$ & 0.007 \\
\hline \multicolumn{4}{|l|}{ Multivariate analysis } \\
\hline \multicolumn{4}{|l|}{ Gender } \\
\hline Male & 1 & - & - \\
\hline Female & 0.143 & $0.040-0.509$ & 0.003 \\
\hline \multicolumn{4}{|l|}{ Age } \\
\hline$<65$ years & 1 & - & - \\
\hline$\geq 65$ years & 2.107 & $1.047-4.241$ & 0.037 \\
\hline \multicolumn{4}{|l|}{ Grading of SCC } \\
\hline Well-moderately differentiated & 1 & - & - \\
\hline Poorly differentiated & 1.941 & $0.836-4.505$ & 0.123 \\
\hline \multicolumn{4}{|l|}{ Invasive depth of tumor } \\
\hline $\mathrm{T} 1+\mathrm{T} 2$ & 1 & - & - \\
\hline $\mathrm{T} 3+\mathrm{T} 4$ & 2.140 & $0.746-6.144$ & 0.157 \\
\hline \multicolumn{4}{|l|}{ Lymph node metastasis } \\
\hline Negative & 1 & - & - \\
\hline Positive & 1.083 & $0.207-5.673$ & 0.925 \\
\hline \multicolumn{4}{|l|}{ Stage (AJCC 7th Ed) } \\
\hline $\mathrm{I}+\mathrm{II}$ & 1 & - & - \\
\hline $\mathrm{III}+\mathrm{IV}$ & 1.597 & $0.260-9.811$ & 0.613 \\
\hline \multicolumn{4}{|l|}{ GRP94 expression } \\
\hline Low & 1 & - & - \\
\hline High & 2.194 & $1.095-4.394$ & 0.027 \\
\hline
\end{tabular}

Abbreviations: CI, confidence interval; AJCC, American Joint Committee on Cancer. 
indicated that GRP94 mediated metastasis ability in ESCC cells.

\section{Silenced GRP94 suppressed proliferation in a zebrafish model}

To further confirm the role of GRP94 in ESCC progression, the xenotransplantation assay was performed in zebrafish system. In brief, scrambled control and GRP94-KD cells were implanted into the embryo yolk. As shown in Figure 4, we compared 1dpi vs. 3dpi stages to demonstrate the proliferative activity between scrambled control and GRP94-KD cells. The cell numbers increase embryo in scrambled control and GRPP94-KD was 72\% vs $60 \%$, indicating that silencing GRP94 caused a decrease in cell growth ability in CE81T cells.

\section{GRP94 was involved in the maintenance of mitochondrial bioenergetics}

Mitochondria function and energy metabolism are key mediators of cancer progression and metastasis. To determine whether GRP94 might influence ESCC metabolism, intact cellular respiration was detected using the Seahorse XF24 Metabolic Flux Analyzer. The data shown in Figure 5 represent the time course of the OCR under basal conditions and following the sequential additions of oligomycin (ATP synthase inhibitor), FCCP (a mitochondrial uncoupling agent) and rotenone (electron transporter channel inhibitor). GRP94-KD cells exhibited significantly lower OCR, basal respiration, maximum respiration, and spare respiratory capacity than scrambled control cells. However, GRP94-KD cells exhibited no difference in ECAR or proton leakage compared to control cells (data not shown). Those results indicated that silencing GRP94 might influence mitochondrial bioenergetics in ESCC cells.

\section{GRP94 influenced mitochondrial structure}

To further confirm the influence of GRP94 in mitochondria, transmission electron microscopy (TEM) was performed. Morphologically, both scrambled control cells and GRP94-KD cells exhibited intact plasma membranes encircling their cellular structures and regularly shaped nuclei within their cellular structures (Figure 6A-6B, N). The numbers of mitochondria in scrambled control and GRP94-KD cells were somewhat comparable (Figure 6A-6B, M). However, the interiors of the mitochondria were significantly different between scrambled control and GRP94-KD cells (Figure 6C-6D). The mitochondria in scrambled control cells exhibited clear and well-defined cristae, formed by inner membrane folding and the major sites of ATP generation. This
A

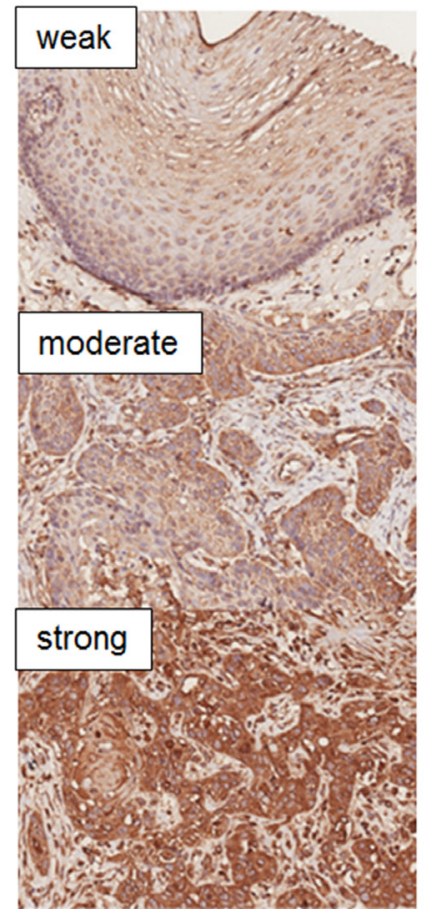

B

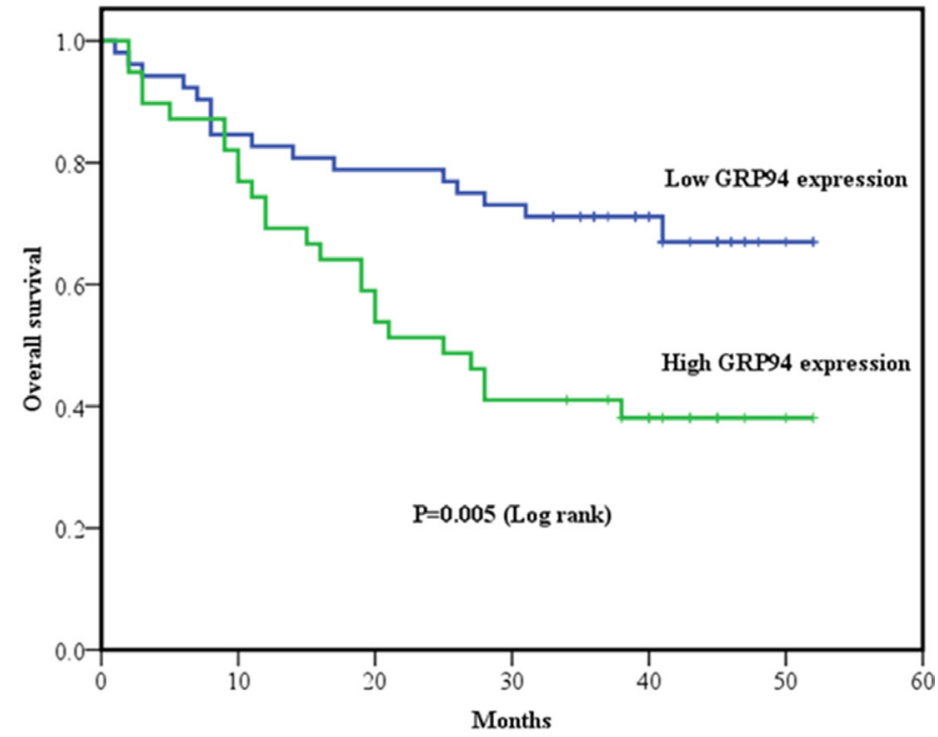

Figure 1: The clinical correlation of GRP94 in ESCC tissue arrays. (A) GRP94 expression in normal esophageal squamous epithelium and squamous cell carcinoma (SCC). Upper: Focal and weak GRP94 expression in normal esophageal squamous epithelium. Middle: Focal and moderate GRP94 expression in esophageal SCC. Bottom: Diffuse and strong GRP94 expression in esophageal SCC (Original magnification, X200). We divided the GRP94 expression scores (0-300) into 2 groups: low expression (0-200) and high expression (201-300). (B) Kaplan-Meier curve of overall survival in esophageal squamous cell carcinomas (ESCC) with low GRP94 and high GRP94 expression. Statistical significance between the two groups $(P=0.005)$. 
observation indicated that mitochondrial function was not disrupted in these cells (Figure 6C, arrows). In contrast, the mitochondria in GRP94-KD cells exhibited missing cristae and several translucent patches where these cristae had been, indicating that mitochondrial function was impaired in these cells (Figure 6D, arrows). These damaged mitochondria were subsequently bound, engulfed and degraded by autophagosomes via mitophagy (Figure $6 \mathrm{E}$, arrows). Higher magnification images revealed remnants of mitochondria in autophagosomes (Figure
6F). Those results suggest that silencing GRP94 might influence the stability of mitochondria in ESCC cells.

\section{Silencing GRP94 influenced AKT and ERK pathway activation}

The AKT and ERK pathways are involved in cancer proliferation and metastasis. We assessed AKT, p-AKT, ERK, and p-ERK levels in scrambled control and GRP94KD cells. Both AKT and p-AKT levels were reduced after
A
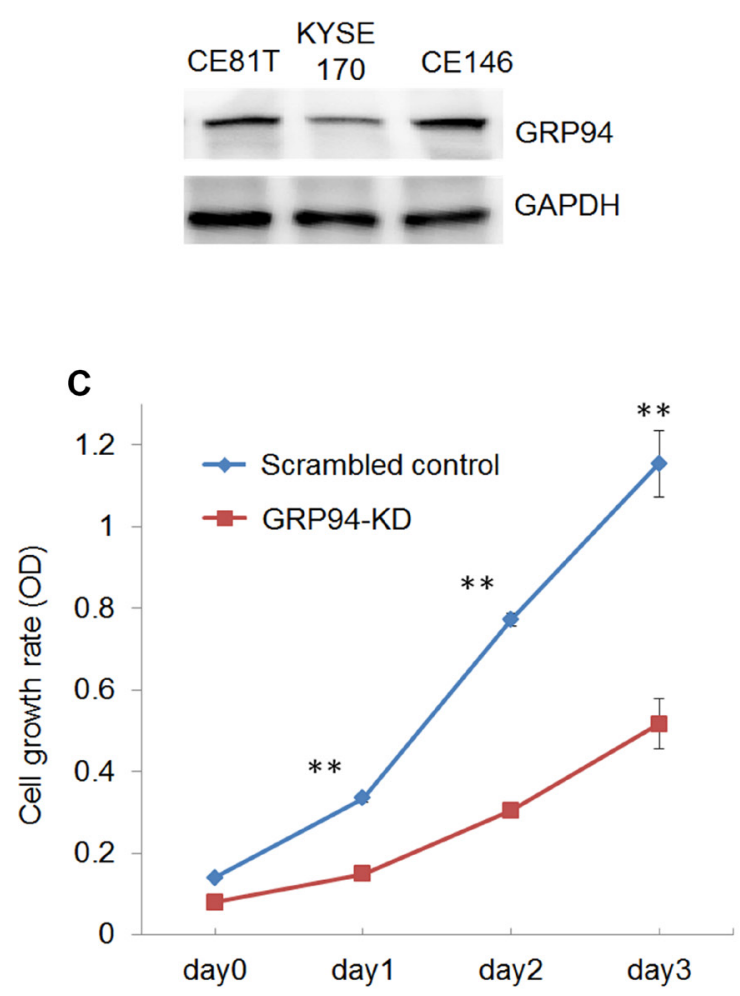

E

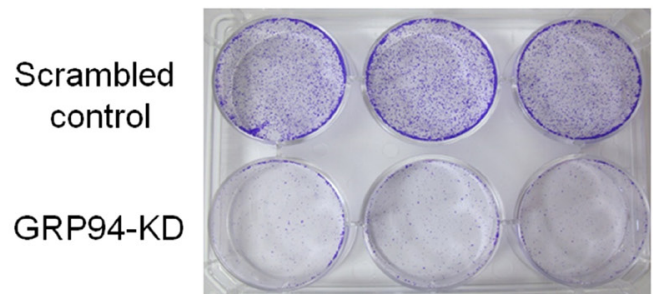

B

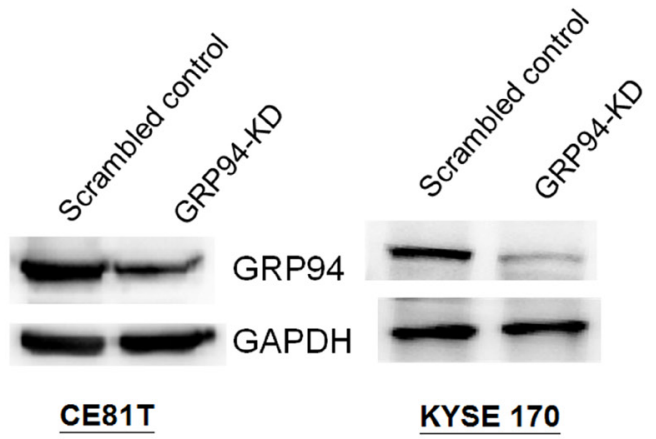

D
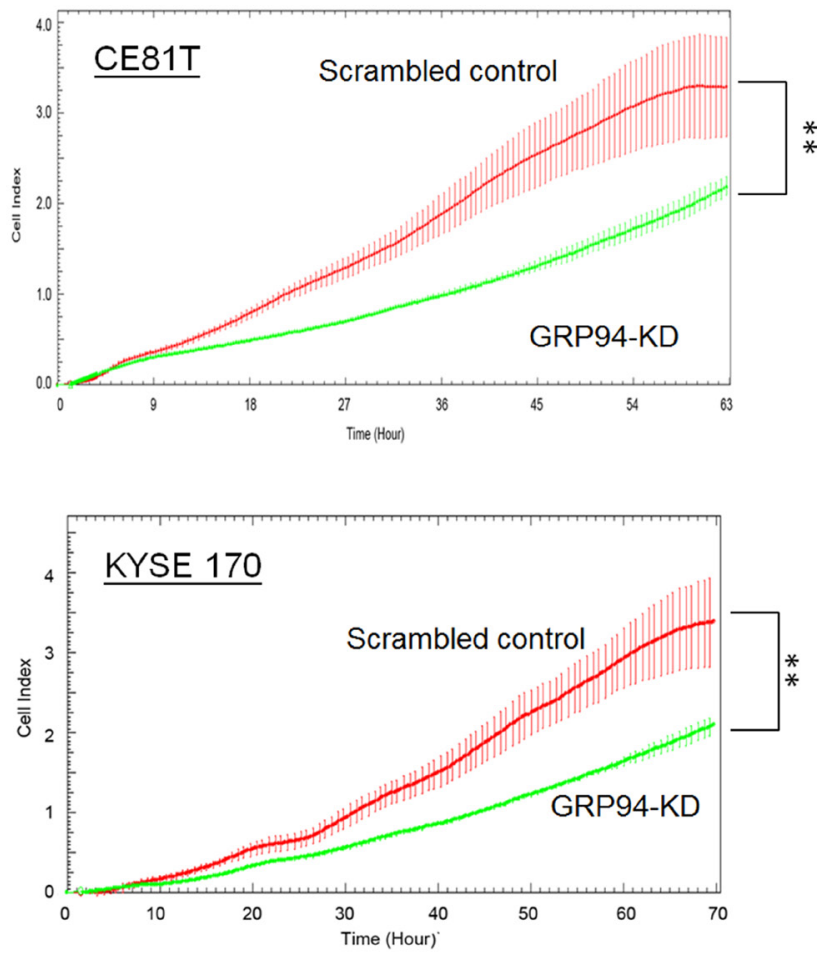

Figure 2: Silencing GRP94 reduced the proliferative activity in ESCC. (A) The level of GRP94 in ESCC cells was determined by western blotting. GAPDH was the internal control. (B) The levels of GRP94 in scrambled control and GRP94-KD cells were determined. (C) The cell growth activity was determined by MTT assay. (D) The x'CELLigence system was applied to determine the proliferation of scrambled control and GRP94-KD CE81T and KYSE 170 cells. (E) Colony formation was performed using the scrambled control and GRP94-KD CE81T cells. All the experiments were repeated at least three times independently. ${ }^{* *}$ indicates $P<0.01$. 
GRP94 knockdown, as shown in Figure 7A. There was no difference in ERK levels between scrambled control and GRP94-KD cells; however, p-ERK levels were dramatically decreased in GRP94-KD cells compared with scrambled control cells. In contrast, JNK pathway activity was not affected by GRP94 knockdown. These findings suggested that GRP94 potentiated cell growth via the AKT and ERK pathways.

\section{Targeting GRP94 caused reductions in AP-1 levels and NF-kB mediated VEGF, IL6 and COX-2 levels}

We next assessed AP-1 (c-Jun and c-Fos) and p38 expression and observed that c-Jun and p38 expression was dramatically suppressed in GRP94-KD cells compared with scrambled control cells (Figure 7B). c-Fos levels were unchanged by GRP94 knockdown. COX-2 is also a key molecular regulator of cancer progression and metastasis and has become an important target in cancer therapy. We assessed COX-2 levels in GRP94-KD and scrambled control cells and observed that down-regulation of GRP94 expression caused dramatic reductions in COX2 levels, as shown in Figure 7B. This observation indicated that GRP94 might regulate COX-2 levels in ESCC cells to facilitate cancer progression and metastasis. We attempted to further determine the downstream target of COX-2. We found that silencing GRP94 caused reductions in VEGF and IL-6 expression in ESCC cells. To further elucidate the upstream regulator of COX-2, we assessed the level of $\mathrm{NF}-\mathrm{kB}$ and found dramatically reduced the levels of NFkB p65 (Figure 7B). Took together, these findings showed that silencing GRP94 might influence VEGF and IL-6 expression levels via the NF-kB/COX-2 axis.

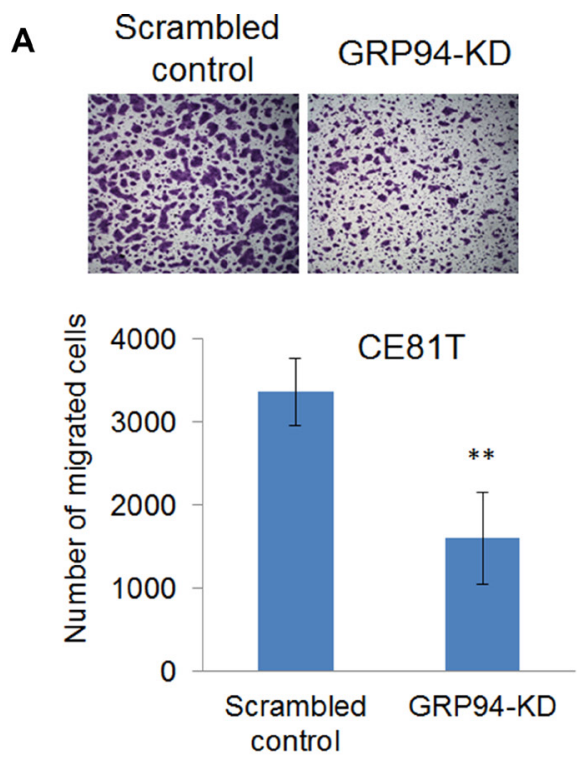

B

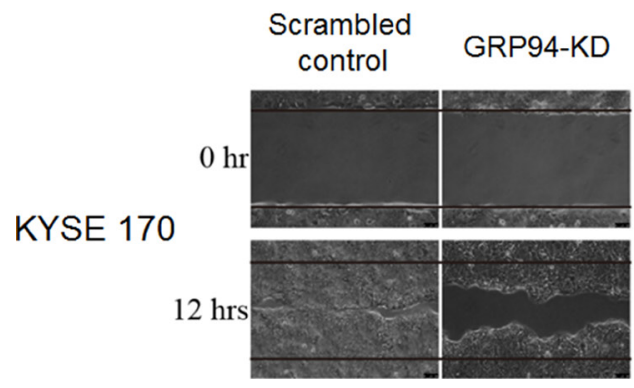

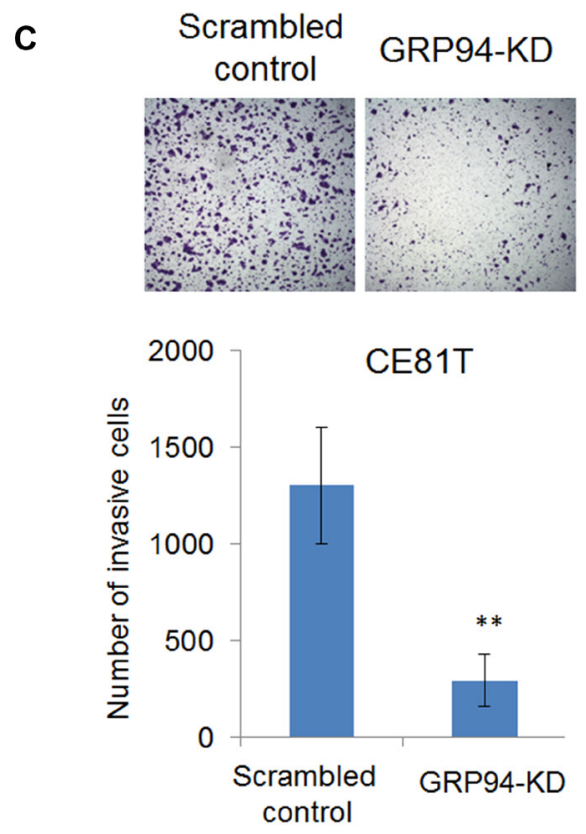

D

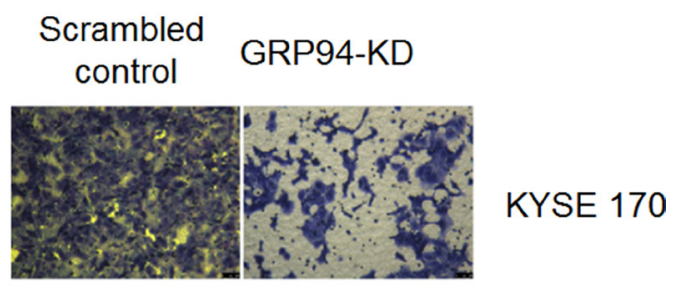

Figure 3: Silencing of GRP94 suppressed metastatic ability in ESCC cells. (A) The migratory ability of scrambled control and GRP94-KD CE81T cells was determined by Transwell system. In wound-healing migratory assay, (B) GRP94-KD KYSE 170 cells showed a slower healing ability than scrambled control cells. (C-D) The invasiveness of scrambled control and GRP94-KD CE81T cells was determined by invasion assay. Silenced GRP94 showed the reduction of invasive ability in CE81T cells (C) and KYSE 170 cells (D). All the experiments were repeated at least three times independently. ${ }^{* *}$ indicates that $P<0.01$. 


\section{AKT and COX2 inhibitor treatments reduced the migration and invasion properties of ESCC cells}

To confirm the role of AKT and COX-2 in the migration and invasion ability of ESCC, we next accessed whether AKT and COX-2 would be important factors regulating migration and invasion properties of CE81T cells (Figure 8). We observed that treated with AKT inhibitor (perifosine, $10 \mu \mathrm{M}$ ) and COX-2 (celecoxib, 10 $\mu \mathrm{M})$ to CE81T cells significantly inhibited migration and invasion at 12 and $48 \mathrm{~h}$, indicating that GRP94 regulated AKT activation and COX-2 levels in ESCC cells to facilitate cancer progression and metastasis.

\section{DISCUSSION}

In general, early diagnosis is the most important issue with respect to ESCC patient management. Most patients diagnosed with ESCC in Taiwan initially present with stage III disease; therefore, the establishment of a

A

D: cell number decreased

S: cell number stay the same

I: cell number increase

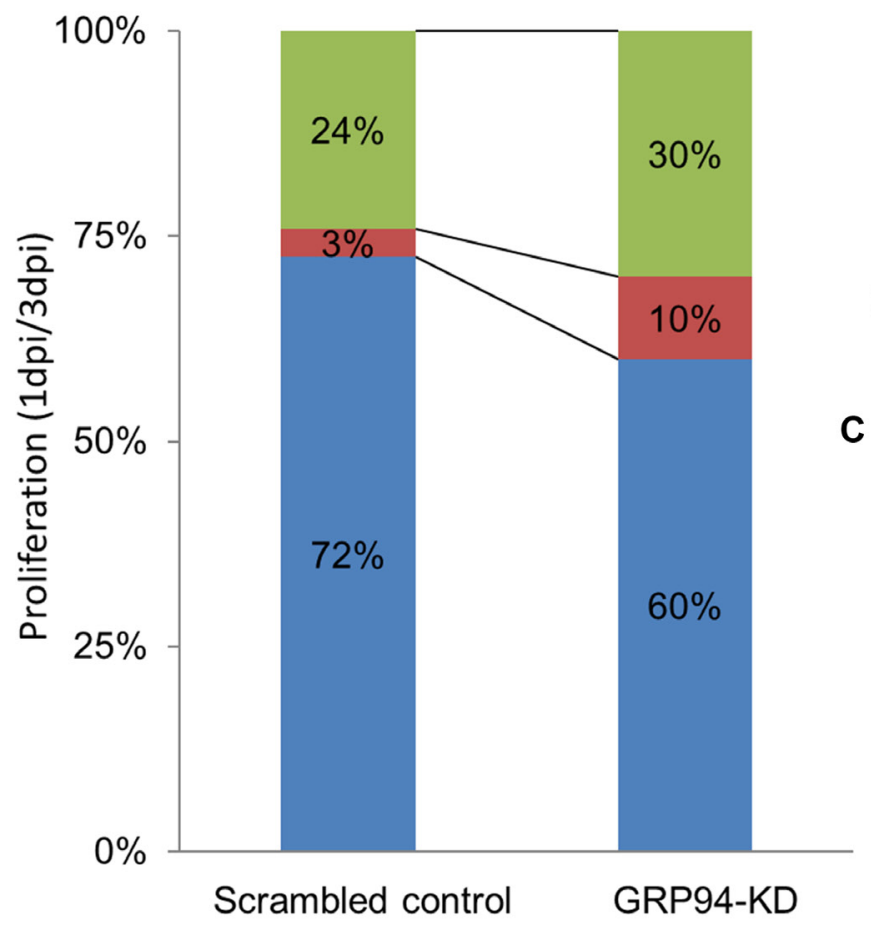

B screening process to facilitate early ESCC diagnosis in affected patients is very important. Regarding ESCC treatment, radical esophagectomy with extensive lymph node dissection, chemoradiotherapy and photodynamic therapy improve the prognosis and quality of life of patients with non-metastatic ESCC [33-35]. However, treatment is much more complicated in ESCC patients with locally advanced, recurrent or metastatic disease. Esophageal cancer treatment is very challenging because the disease recurrence rate remains high, and recurrence is often accompanied by distant metastasis to the liver or lungs [36]. Specific prognostic or therapeutic biomarkers of esophageal cancer are therefore urgently needed.

GRPs are stress-inducible chaperones residing mainly in the ER and mitochondria. Previous studies have demonstrated that GRPs play specific roles in tumorigenesis [29, 37], progression and metastasis $[38,39]$. Many reports have shown that GRPs are therapeutic targets for cancer treatment, and many different compounds targeting GRPs are being developed. Our previous study showed that GRP94-KD cervical

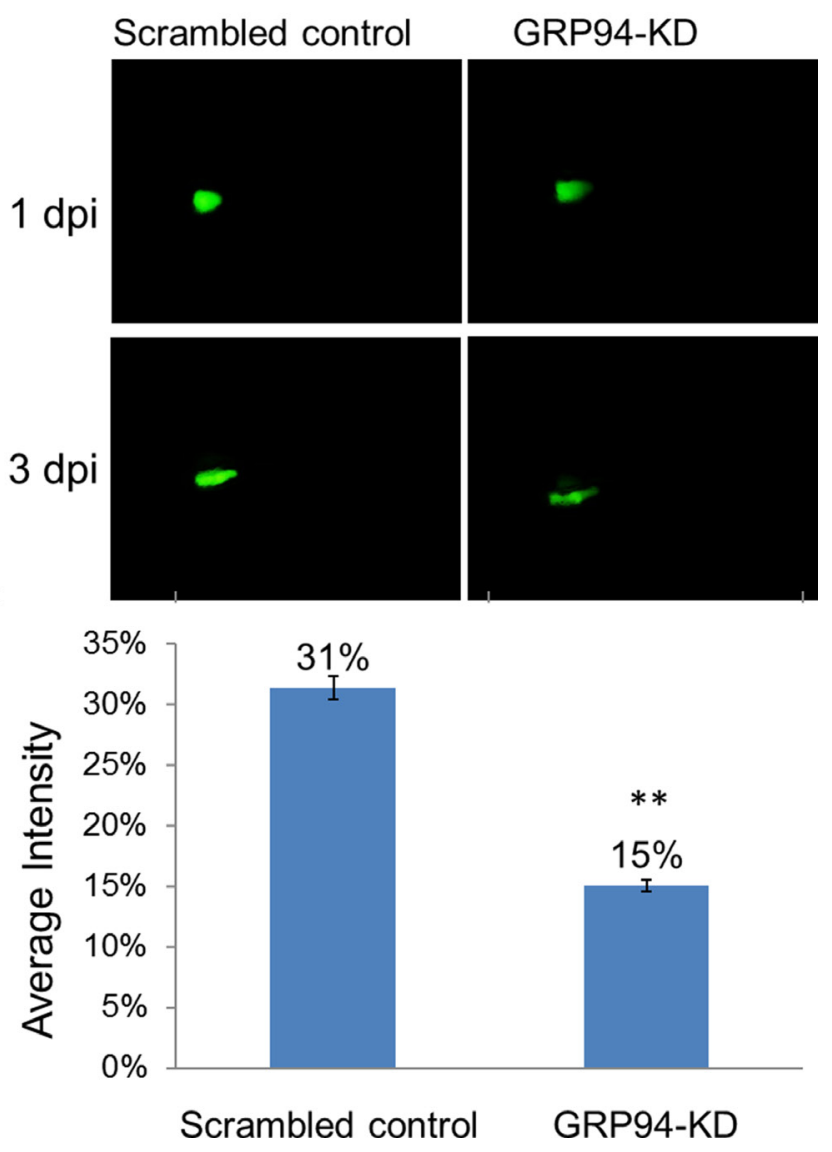

Figure 4: Silenced GRP94 suppressed proliferation in a zebrafish model. (A) Scrambled control and GRP94-KD cells were injected into embryos. The embryos were checked for fluorescent cells at $2 \mathrm{~h}$ post-transplantation and were examined at one and three days post-injection ( 1 dpi and 3 dpi). Comparison of the 1 dpi vs. 3 dpi stages showed differences in proliferative activity between scrambled control and GRP94-KD cells. (B-C) The image of the embryo was obtained using an immunofluorescence microscope. The fluorescence intensity was quantified. The data are presented as the means of 6 experiments \pm SD. ${ }^{* *} P<0.01$. 
cancer cells are more chemoresistant to docetaxel due to suppression of the mitochondrial caspase-mediated cell death pathway [16]. In both human ESCC and adenocarcinoma [27, 40], GRP94 protein expression levels are higher in cancer tissue than in adjacent normal mucosal tissue. The role of GRP94 in esophageal cancer proliferation and migration is not clear. We demonstrated a significant correlation between GRP94 expression and ESCC development and progression (Figure 1), as the results of our in vitro assays suggested that GRP94 depletion could inhibit cell growth and metastasis. We also observed that GRP94 mediated VEGF expression levels via the NF-kB/COX-2 axis (Figure 7). This is the first evidence of a regulatory relationship between GRP94 and $\mathrm{NF}-\mathrm{kB} / \mathrm{COX}-2$ axis.

COX-2, an isoform of COX, catalyzes the conversion of arachidonic acid into inflammatory PGs, which play important roles in carcinogenesis. Extensive evidence gathered over the past several decades indicates that COX-2 expression is enhanced in many premalignant tissues and malignant tumors, including Barrett's esophagus and esophageal cancer [41, 42].
Relatively high COX-2 expression levels have been observed in advanced-stage lung cancer with lymph node metastases [43], and further studies indicate that COX-2 overexpression is associated with angiogenesis [44] as well as tumor invasion and metastasis [45, 46]. COX-2 also modulates P-glycoprotein (MDR-1), which contributes to drug resistance [47]. COX-2-derived PGs play an important role in regulating esophageal tumor cell proliferation and apoptosis [48]. Thus, COX-2 inhibition may be useful in the treatment of esophageal cancer. Large-scale epidemiological studies have indicated that regular use of non-steroidal antiinflammatory drugs, such as aspirin, which mainly acts by inhibiting COX-1 and COX-2, may reduce the risk of esophageal cancer [49], as selective COX-2 inhibition not only inhibits tumor invasiveness and metastasis in colon cancer cells [50] but also induces apoptosis in multidrug-resistant cell lines [51].

It is well-known that the energy requirements of rapidly growing tumor cells are met by predominantly glycolytic metabolism with high-energy requirements through the use of mitochondrial respiration [52]. In
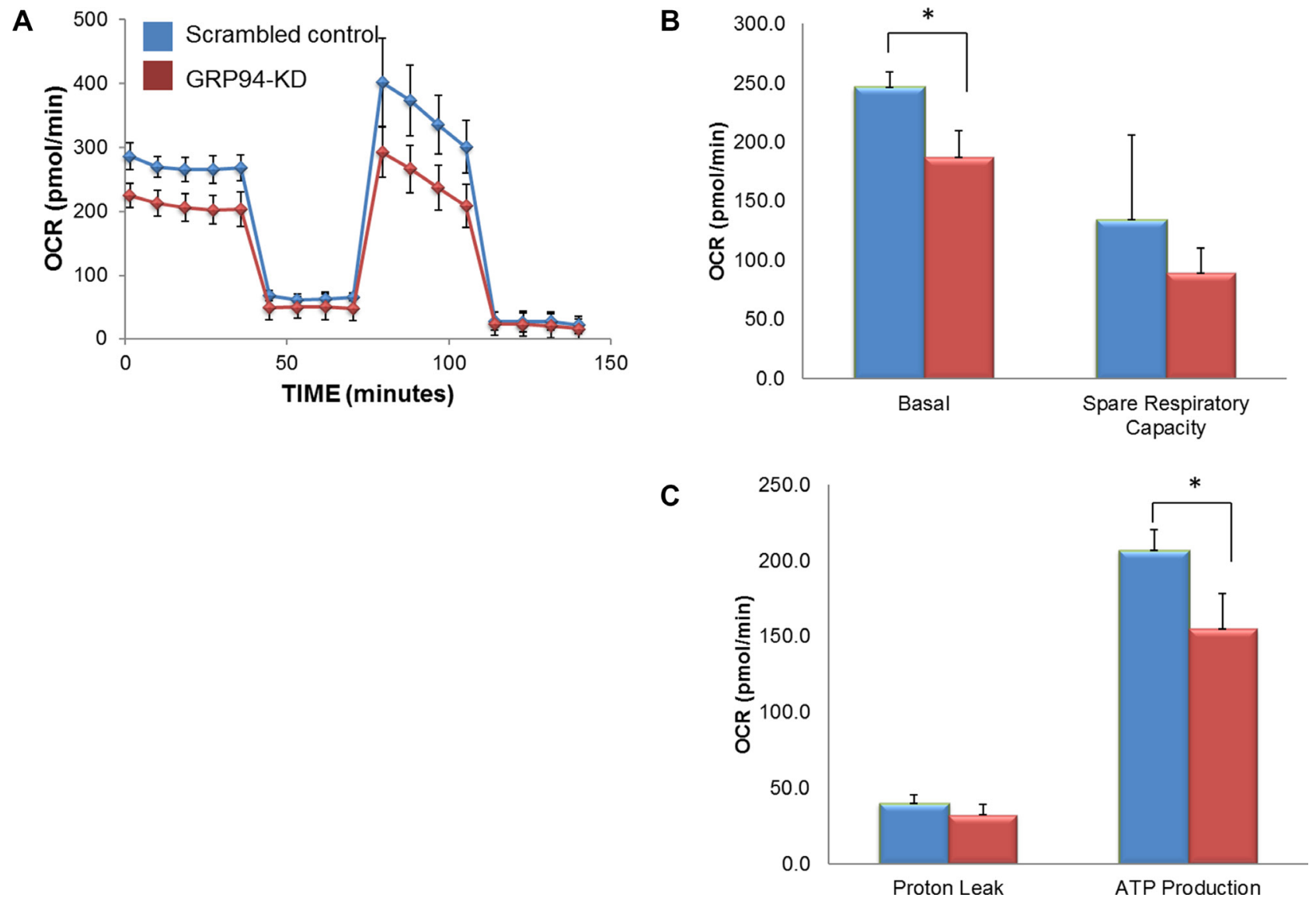

Figure 5: GRP94 silencing influenced mitochondrial respiration. The cell metabolism of scrambled control and GRP94KD CE81T cells was assessed using the XFe24 Analyzer. (A) Mitochondrial respiration was measured by the oxygen consumption rate (OCR). (B-C) After establishing the baseline, ATP production, maximal respiration, spare respiratory capacity and proton leak were measured following sequential addition of oligomycin (ATP synthase inhibitor), FCCP (a mitochondrial uncoupling agent) and rotenone (electron transporter channel inhibitor). Experiments were repeated three times with similar data trends, and the reported values are from a representative experiment. "indicates $P<0.05$. 
addition, increasing evidence suggests a strong association between the energy metabolism of tumor cells and tumor progression and development [53-55]. The glucose regulated protein, GRP94 is a stress-inducible molecular chaperone that is mainly localized in the cytosol and nucleus. GRP94 is also found in the endoplasmic reticulum (ER) and mitochondria, which are key organelles regulating protein quality control and metabolic balance, maintaining the integrity and homeostasis of the ER and mitochondria under physiological and pathological conditions [56-58]. Structural and functional analyses reveal zones of close contact between the ER and mitochondria [59]. Signaling from the ER to mitochondria can be critical in the induction of mitochondrial dependent cell death pathways [60]. Thus, the lack of GRP94 expression not only causes ER stress and downstream ER stress-responsive genes to
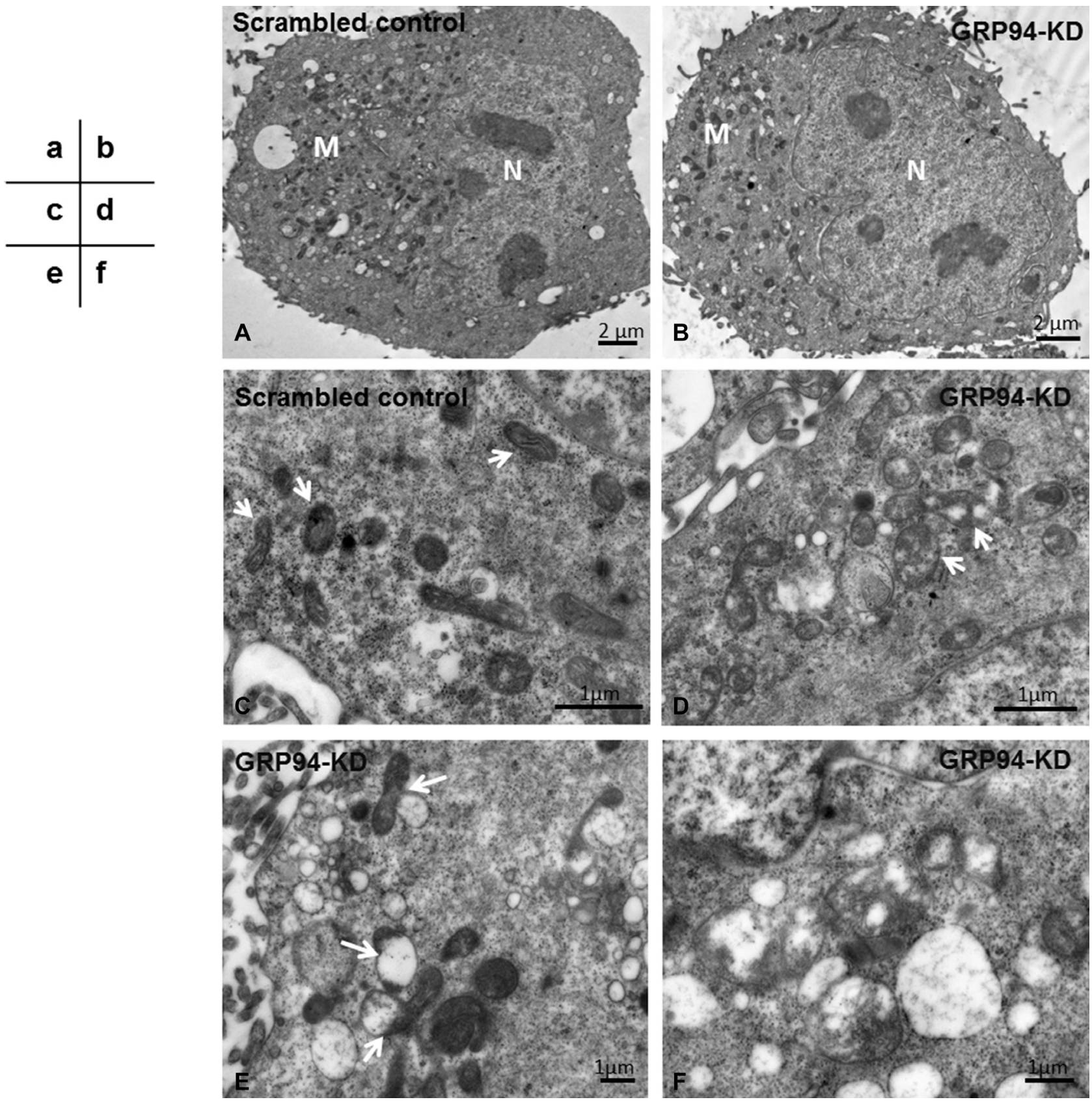

Figure 6: Silencing GRP94 promoted mitophagy. (A-B) The mitochondria (M) were located in the cytoplasm outside of nuclei (N). Under low magnification, the numbers of mitochondria in the scrambled control and GRP94-KD CE81T cells were similar. (C) Under higher magnification, the mitochondria in scrambled control cells were clear and had well-defined cristae (arrows). (D) The mitochondria in GRP94-KD cells had lost a portion of the cristae, leaving translucent patches (arrows). The mitochondria in GRP94-KD cells had been degraded by autophagosomes. (E) The impaired mitochondria were attached to and digested by autophagosomes (arrows). (F) Higher magnification showing mitochondrial remnants engulfed by autophagosomes. 
bolster ER protein-folding capacity, but it also disturbs mitochondrial structural and functional characteristics to trigger mitochondrial dependent apoptosis. Accordingly,

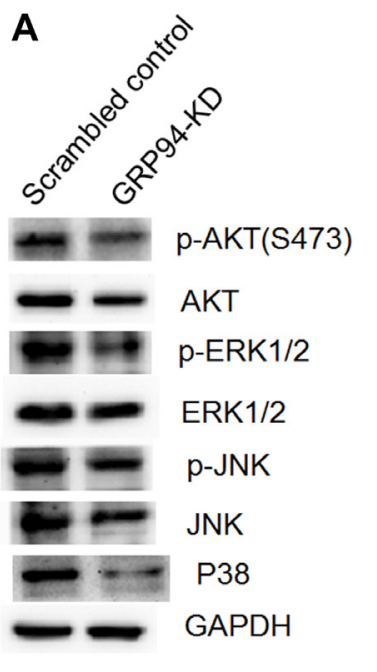

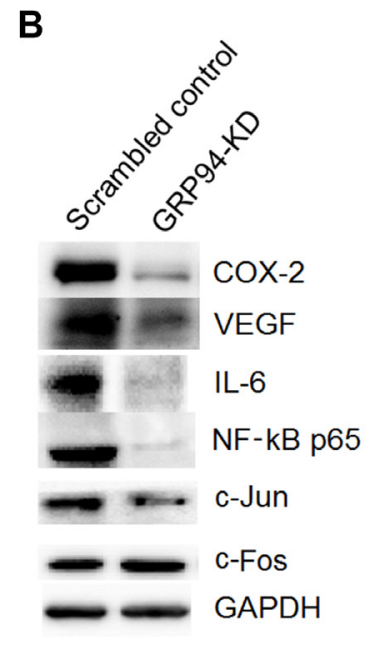

GRP94 overexpression is associated with lymph node metastasis and carcinoma recurrence in gastric carcinomas [20], whereas silencing of GRP94 dramatically inhibits

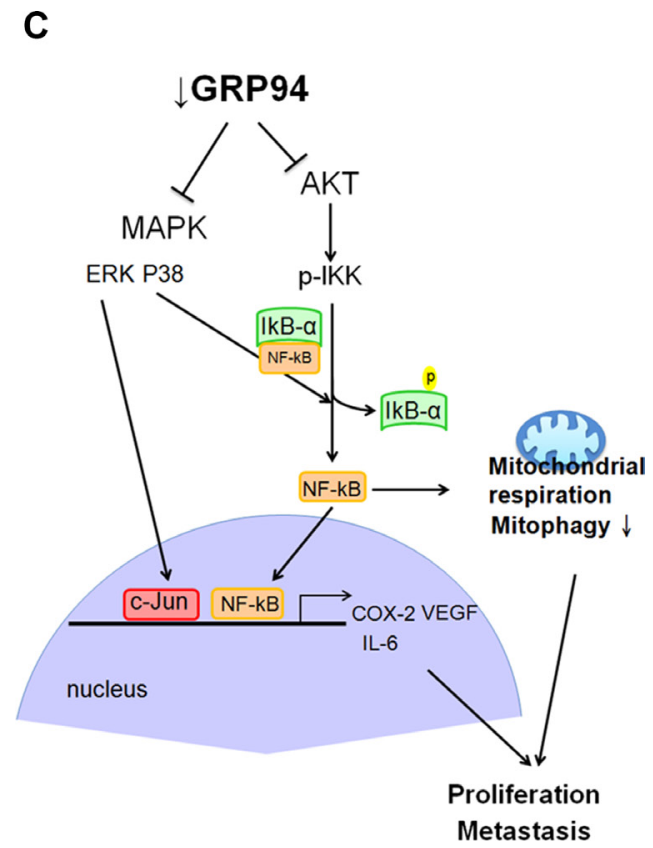

Figure 7: Silencing GRP94 suppressed the AKT and MAPK-mediated pathways. (A) The levels of AKT, p-AKT, JNK, p-JNK, p38, ERK and p-ERK were determined. Activation of AKT and ERK was suppressed in GRP94-silenced cells. (B) The levels of COX-2, VEGF, IL-6, c-Jun, c-Fos, and NF-kB were determined by western blotting. (C) Schematic showing how silencing GRP94 may inhibit the AKT and MAPK pathways. The subsequent reduction of COX-2, IL-6, and VEGF may be due to the reduction of NF-kB activation and AP-1 production.

A

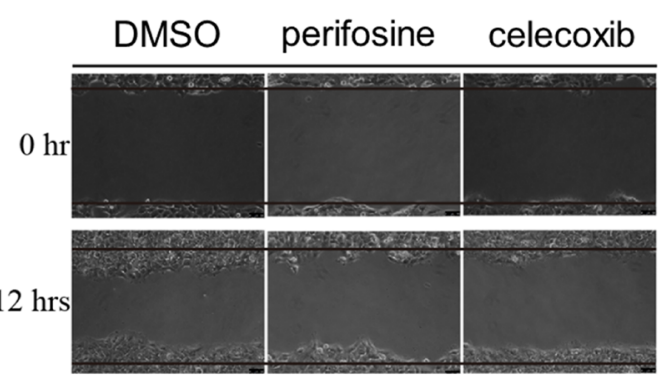

B
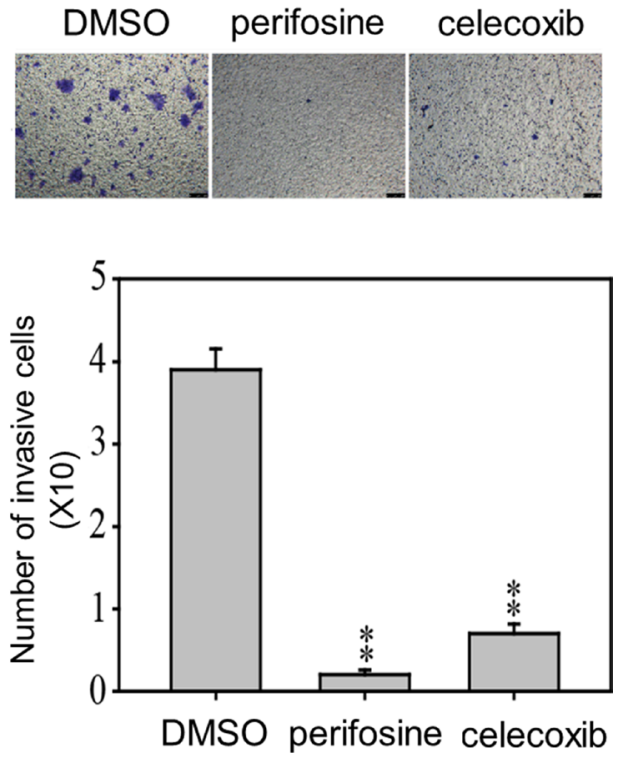

Figure 8: AKT and COX-2 inhibitors suppress the metastatic and invasion abilities of CE81T cells. The migration (A) and invasion (B) abilities of CE81T cells in the presence of $10 \mu \mathrm{M}$ AKT inhibitor (perifosine) or $10 \mu \mathrm{M}$ COX-2 inhibitor (celecoxib) were determined by wound healing and transwell assays. In the invasion assay, the invaded cells were stained with $0.1 \%$ crystal violet and evaluated by microscopy. All experiments were repeated at least three times independently. ${ }^{* *}$ indicates $P<0.01$. 
cancer cell migration and proliferation abilities in vitro [61]. The present findings support previous reports showing that higher GRP94 expression levels are associated with lower overall survival and higher lympho-node metastasis, while silencing GRP94 impairs mitochondria by reducing basal respiration and ATP production in ESCC cells. GRP94 knockdown-induced ER stress dysregulation may be directly linked to mitochondria dysfunction in ESCC cells, resulting in suppression of cancer growth and metastatic potential.

Our findings indicate that GRP94 depletion caused a reduction in the expression of VEGF and its downstream target molecule COX-2, which might be the major factor causing suppression of tumor growth and metastasis. This is the first study to demonstrate that GRP94 influences IL-6 and VEGF expression in ESCC. To understand how GRP94 regulates VEGF expression, we conducted a miRNA analysis to determine whether GRP94 depletion suppresses VEGF expression by altering miRNA levels. Our results indicate that the level of miR107, but not miR125a, was up-regulated dramatically due to GRP94 depletion in ESCC (data not shown). However, additional experiments are necessary to determine how GRP94 influences miR107 levels. In conclusion, we observed that GRP94 depletion induces miR107 up-regulation and VEGF suppression in ESCC cells. Clinical biomarkers shown to be predictive of certain epithelial tumors, such as EGFR or KRAS mutations in colon cancer, are infrequent and/or not predictive of esophageal cancers [62]. The PI3K/AKT pathway plays a crucial role in endothelial cell proliferation and differentiation [63]. AKT is a client protein of HSP90, the functionality of which is required for AKT pathwaymediated transduction of growth factor signaling [64]. The current study further demonstrates that GRP94 depletion suppresses AKT and ERK pathway activation.

\section{MATERIALS AND METHODS}

\section{Chemicals and reagents}

Triton X-100, Tris-HCl, neomycin, Trypan blue, EDTA, ribonuclease-A, and dimethyl sulfoxide (DMSO) were obtained from Sigma Chemical Co. (St. Louis, MO, USA). AKT inhibitor (perifosine) and COX-2 (celecoxib) was purchased from Selleckchem (Huston, TX, USA). Antibodies against GRP94, c-Fos, c-Jun, NF-kB and GAPDH were purchased from Santa Cruz Biotechnology, Inc. (Santa Cruz, CA, USA). The anti-VEGF antibody was purchased from Millipore, and antibodies against JNK, p38, p-AKT, AKT, p-ERK, and ERK were purchased from Cell Signaling Technology. The anti-COX2 and p-JNK antibody were purchased from Abcam. The anti-IL6 antibody was purchased from Genescript.

\section{Cell culture}

Human ESCC cells (CE81T and CE146T) were purchased from the Food Industry Research and
Development Institute (Hsinchu City, Taiwan). KYSE 170 cell was a gift from Pro. Yi-Ching Wang (National Cheng Kung University) and Prof. Ruo-Kai Lin (Taipei Medical University). These cells were maintained in Dulbecco's Modified Eagle Medium (DMEM) (Gibco BRL, Grand Island, NY, USA) supplemented with $10 \%$ fetal calf serum (Gibco BRL, Grand Island, NY, USA), 4 mM L-glutamine, $100 \mu \mathrm{M}$ non-essential amino acids, and $2 \%$ penicillinstreptomycin $(10,000 \mathrm{U} / \mathrm{mL}$ penicillin and $10 \mathrm{mg} / \mathrm{mL}$ streptomycin) in a humidified incubator containing 5\% $\mathrm{CO}_{2}$ at $37^{\circ} \mathrm{C}$, as previously described $[65,66]$.

\section{Tissue samples and immunohistochemistry}

Two sets of ESCC tissue microarrays (catalog no. HEso-Squ172Sur-01 and HEso-Squ172Sur-02) were purchased from Shanghai Outdo Biotech Co. (Shanghai, China). The pathologic diagnoses of these cases were microscopically reconfirmed. The sections were deparaffinized, rehydrated, and blocked with 3\% hydrogen peroxide. Heat-induced antigen retrieval was performed in citric acid buffer ( $\mathrm{pH} 6.0$ ) at $121^{\circ} \mathrm{C}$ for 10 min using a decloaking chamber (Biocare Medical, Concord, CA, USA), after which the sections were incubated with goat polyclonal GRP94 antibodies (catalog No.: sc1794, 1:600; Santa Cruz Biotechnology, Dallas, TX, USA) at $4^{\circ} \mathrm{C}$ overnight. Then, the sections were incubated with a biotin-conjugated rabbit anti-goat antibody (catalogue No.: AP106B, 1:500, Chemicon International, Billerica, MA, USA) at room temperature for 30 min before being incubated with a prediluted streptavidin-horseradish peroxidase complex (Dako, Glostrup, Denmark) at room temperature for $10 \mathrm{~min}$. The antigens were revealed by addition of 3,3'-diaminobenzidine, followed by counterstaining with hematoxylin. Appropriate positive and negative controls were included in these assays. Both the intensity and the extent of GRP94 expression in carcinoma cells were evaluated and scored using a previously described method [67]. Cytoplasmic staining intensity was scored semiquantitatively as follows: 0 point, negative; 1 point, weakly positive; 2 points, moderately positive; and 3 points, strongly positive. The percentage of positive tumor cells $(0-100 \%)$ was multiplied by the GRP94 staining intensity; therefore, the overall score ranged from 0 to 300 . We subsequently divided the GRP94 expression scores (0$300)$ into the following 2 groups: a low expression (0-200) group and a high expression (201-300) group.

\section{GRP94-knockdown esophageal cell line generation}

The method used to generate GRP94-knockdown (GRP94-KD) ESCC cells with small hairpin RNA (shRNA) was modified from that used in a previous report [24, 25]. GRP94-specific shRNA was purchased from the National RNAi Core Facility, Academia Sinica, Taiwan. The target 
mRNA sequence for the human GRP94 (NM_003299) gene was 5'-GCGAGACTCTTCAGCAACATA-3' and the sequence of the non-target shRNA control vector (SHC002) was 5 '-caacaagatgaagagcaccaa-3' (Sigma Chemical Co., St. Louis, MO). The plasmids were transfected into ESCC cells using a Neon transfection system (Invitrogen Life Technologies, Grand Island, NY), as described previously $[24,25]$. Stably transfected cells were selected using puromycin for two weeks, and GRP94 expression was verified by quantitative real-time PCR and western blotting.

\section{Protein extraction and western blot analysis}

Cell lysates were prepared using cell lysis buffer containing protease inhibitors (Complete Protease Inhibitor Tablets, Boehringer Mannheim, Indianapolis, IN). The protein samples were separated by $10 \%$ SDSPAGE under reducing conditions and electrotransferred onto PVDF membranes (Bio-Rad Laboratories). Immunoblotting was performed using specific antibodies, as described in the Figure legends, and horseradish peroxidase (HRP)-conjugated secondary antibodies (1:5000). The bands were visualized with enhanced chemiluminescence reagent (GE Healthcare, Piscataway, $\mathrm{NJ}$ ) and detected using a VersaDoc 5000 imaging system (Bio-Rad Laboratories) [24, 25].

\section{Cell proliferation assays using an xCELLigence biosensor system}

Experiments were conducted using an RTCA DP instrument (AECE Biosciences, Inc., San Diego, CA), as previously described $[24,25]$. Growth curves were constructed using 16-well plates (E-plate 16, AECE Biosciences, Inc.). Cells were seeded in an E-plate 16 at a density of 10,000 cells/well in FCS-containing medium. The plate was subsequently assessed once every $30 \mathrm{~s}$ for $4 \mathrm{~h}$ and once every half $\mathrm{h}$ thereafter. The data were analyzed using RTCA software version 1.2 (supplied with the instrument).

\section{Cell viability assay}

Cells were plated at a density of $2 \times 10^{4}$ cells/well in 24-well plates and incubated overnight in a $37^{\circ} \mathrm{C}, 5 \%$ $\mathrm{CO}_{2}$ incubator. The medium was aspirated, the remaining cells were further incubated with $0.25 \mathrm{mg} / \mathrm{mL}$ MTT for 1 $\mathrm{h}$ and subsequently extracted with DMSO, and the color change in the extract was measured at $550 \mathrm{~nm}$ using a spectrophotometer.

\section{Colony formation}

A total of 1000 cells were seeded per well in a 6-well plate and cultivated for 2 weeks. Subsequently, the cells were fixed and stained with crystal violet. Quantification of crystal violet staining were observed under a phase contract microscope.

\section{Transwell migration assay}

In vitro cell migration was investigated using an $8-\mu \mathrm{m}$ BD Falcon ${ }^{\mathrm{TM}}$ culture insert (BD Biosciences), as previously described [66]. Specifically, $1 \times 10^{5}$ cells were suspended in $500 \mu \mathrm{L}$ of serum-free media and then seeded into the upper compartment of the chamber. The lower compartment was filled with $1 \mathrm{~mL}$ of $10 \%$ FCScontaining media. After $24 \mathrm{~h}$ of incubation, the migrated cells on the reverse side of the membrane were stained with $0.1 \%$ crystal violet, and cell images were captured using an Olympus IX71 inverted microscope (Olympus Corp., Tokyo, Japan), under which the cells were counted at 100 -fold magnification.

\section{Invasion assay}

In vitro cell invasion assay was performed using an $8-\mu \mathrm{m}$ BD Falcon ${ }^{\mathrm{TM}}$ cell culture insert (BD Biosciences) [68]. Aliquots of $1 \times 10^{5}$ cells were seeded into the upper compartment of the chamber. The lower compartment was filled with DMEM medium supplemented with $10 \%$ FCS. After $24 \mathrm{~h}$ of incubation, the noninvasive cells were removed from the upper surface of the membrane, while the invasive cells were stained with $0.1 \%$ crystal violet. Cell images were captured using an Olympus IX71 inverted microscope (Olympus Corp., Tokyo, Japan), under which the cells were counted at 100-fold magnification.

\section{Seahorse XF24 metabolic flux analysis}

Intact cellular respiration was detected using the Seahorse XF24 Metabolic Flux Analyzer (Seahorse Bioscience, Chicopee, MA, USA). The cells were cultured in XF24-well microplates coated with CELLTAK (BD Biosciences). Baseline measurements were recorded before the addition of $3 \mu \mathrm{M}$ oligomycin, $1 \mu \mathrm{M}$ carbonyl cyanide-4-(trifluoromethoxy)phenylhydrazone (FCCP), and $1 \mu \mathrm{M}$ rotenone. The oxygen consumption rate (OCR), extracellular acidification rate (ECAR), an indicator of lactic acid production or glycolysis), spare respiratory capacity, and proton leakage were automatically calculated and recorded using Seahorse XF24 software. The percent change from the basal rate was calculated as the change in the rate divided by the average baseline rate.

\section{Xenotransplantation}

The assay was performed by Taiwan Zebrafish Core Facility - Human Disease Model Resource Center. In brief, at two-days post-fertilization (dpf), the zebrafish embryos were 
dechorionated and subsequently anesthetized with tricaine (0.04 mg/ml, Sigma, St. Louis, MO, USA). Scrambled control or GRP94-KD CE81T cells were harvested, and labeled with CM-Dil (red fluorescence) (Vybrant; Invitrogen, Carlsbad, CA, USA). Approximately 200 cells (4.6 nl) were implanted into the yolk of each 2-dpf embryo using a Nanoject II Auto-Nanoliter Injector (Drummond Scientific, Broomall, PA, USA). After injection, the zebrafish embryos were washed once with fish water and incubated for $1 \mathrm{~h}$ at $28^{\circ} \mathrm{C}$. The embryos were checked for fluorescent cells at $2 \mathrm{~h}$ post-transplantation and were examined at one and three-days post-injection (1dpi and $3 \mathrm{dpi}$ ) by fluorescence microscopy.

\section{Transmission electron microscopy}

The cells were fixed with $2 \%$ paraformaldehyde and 2\% glutaraldehyde (Electron Microscopy Sciences, PA, USA) in $0.1 \mathrm{M}$ cacodylate buffer overnight at $4^{\circ} \mathrm{C}$, after which the cells were washed three times with 0.1 $\mathrm{M}$ cacodylate buffer for $10 \mathrm{~min}$ each. The cells were subsequently fixed with $1 \% \mathrm{OsO} 4$ for $1 \mathrm{~h}$ at RT and washed three times with $0.1 \mathrm{M}$ cacodylate buffer for 10 min each. Dehydration was performed by incubating the samples in ascending EtOH concentrations of 50, $60,70,80,90,95$, and $100 \%$ to completely remove residual water from the cells. The samples were then infiltrated with a mixture of absolute EtOH and Epon 812 resin (Electron Microscopy Sciences, PA, USA) at ratios of $3: 1,1: 1$, and $1: 3$ for $2 \mathrm{~h}$ at each step. Pure resin was then applied twice, first for $4 \mathrm{~h}$ and then overnight, with gentle agitation. The cells were then embedded in fresh pure resin and polymerized at $60^{\circ} \mathrm{C}$ overnight. Ultrathin sections were generated with a Leica EM UC6 ultramicrotome and contrasted with uranyl acetate and lead citrate. These sections were then viewed under a Hitachi H-7500 transmission electron microscope.

\section{Statistical analysis}

Patient clinicopathological characteristics and GRP94 expression levels were compared using chi-square tests for categorical data and two-tailed Student's t tests for continuous data. Overall survival curves were generated using the Kaplan-Meier method, and the difference in survival between the low GRP94 expression group and the high GRP94 expression group was evaluated via the logrank test. A Cox proportional hazards model was utilized to identify clinicopathological factors significantly associated with patient prognosis. $P<0.05$ was considered statistically significant. All statistical calculations were performed using SPSS Statistics 17.0 software (SPSS Inc. Chicago, IL, USA).

\section{Author contributions}

YJ Chang, CY Huang, CC Tu, CH Lee, and PL Wei conceived the idea of the project and wrote the manuscript. CY Huang, CC Tu, CH Lee, and YJ Chang designed and performed the experiments. CY Huang, $\mathrm{CC} \mathrm{Tu}, \mathrm{CH} \mathrm{Wu}, \mathrm{PL}$ Wei, and YJ Chang analyzed the experimental data. CY Huang, MT Huang, PL Wei, and YJ Chang discussed the results and commented on the paper.

\section{ACKNOWLEDGMENTS AND FUNDING}

We thanked for Pro. Yi-Ching Wang (National Cheng Kung University) and Prof. Ruo-Kai Lin (Taipei Medical University) to provide us the KYSE 170 cells for this study. This study was supported grants from Ministry of Science and Technology, ROC (grant No. MOST1052320-B-038-046) and Taipei Medical University (TMU106-AE1-B03).

\section{CONFLICTS OF INTEREST}

The authors declare no competing financial interests.

\section{REFERENCES}

1. Tran GD, Sun XD, Abnet CC, Fan JH, Dawsey SM, Dong ZW, Mark SD, Qiao YL, Taylor PR. Prospective study of risk factors for esophageal and gastric cancers in the Linxian general population trial cohort in China. Int J Cancer. 2005; 113:456-63. https://doi.org/10.1002/ijc.20616.

2. Lee CH, Lee JM, Wu DC, Hsu HK, Kao EL, Huang HL, Wang TN, Huang MC, Wu MT. Independent and combined effects of alcohol intake, tobacco smoking and betel quid chewing on the risk of esophageal cancer in Taiwan. Int $\mathrm{J}$ Cancer. 2005; 113:475-82. https://doi.org/10.1002/ijc.20619.

3. Wu M, Liu AM, Kampman E, Zhang ZF, Van't Veer P, Wu DL, Wang PH, Yang J, Qin Y, Mu LN, Kok FJ, Zhao JK. Green tea drinking, high tea temperature and esophageal cancer in high- and low-risk areas of Jiangsu Province, China: a population-based case-control study. Int J Cancer. 2009; 124:1907-13. https://doi.org/10.1002/ijc.24142.

4. Engel LS, Chow WH, Vaughan TL, Gammon MD, Risch HA, Stanford JL, Schoenberg JB, Mayne ST, Dubrow R, Rotterdam H, West AB, Blaser M, Blot WJ, et al. Population attributable risks of esophageal and gastric cancers. J Natl Cancer Inst. 2003; 95:1404-13.

5. Streitz JM Jr. Barrett's esophagus and esophageal cancer. Chest Surg Clin N Am. 1994; 4:227-40.

6. Polednak AP. Trends in survival for both histologic types of esophageal cancer in US surveillance, epidemiology and end results areas. Int J Cancer. 2003; 105:98-100. https:// doi.org/10.1002/ijc.11029.

7. Enzinger PC, Mayer RJ. Esophageal cancer. N Engl J Med. 2003; 349:2241-52. https://doi.org/10.1056/ NEJMra035010.

8. Ando N, Ozawa S, Kitagawa Y, Shinozawa Y, Kitajima M. Improvement in the results of surgical treatment of 
advanced squamous esophageal carcinoma during 15 consecutive years. Ann Surg. 2000; 232:225-32.

9. Ribeiro $\mathrm{U}$ Jr, Finkelstein $\mathrm{SD}$, Safatle-Ribeiro AV, Landreneau RJ, Clarke MR, Bakker A, Swalsky PA, Gooding WE, Posner MC. p53 sequence analysis predicts treatment response and outcome of patients with esophageal carcinoma. Cancer. 1998; 83:7-18.

10. Schneider S, Uchida K, Brabender J, Baldus SE, Yochim J, Danenberg KD, Salonga D, Chen P, Tsao-Wei D, Groshen S, Hoelscher AH, Schneider PM, Danenberg PV. Downregulation of TS, DPD, ERCC1, GST-Pi, EGFR, and HER2 gene expression after neoadjuvant three-modality treatment in patients with esophageal cancer. J Am Coll Surg. 2005; 200:336-44. https://doi.org/10.1016/j. jamcollsurg.2004.10.035.

11. Sudo T, Mimori K, Nagahara H, Utsunomiya T, Fujita H, Tanaka Y, Shirouzu K, Inoue H, Mori M. Identification of EGFR mutations in esophageal cancer. Eur J Surg Oncol. 2007; 33:44-8. https://doi.org/10.1016/j.ejso.2006.10.034.

12. Grugan KD, Nakagawa H. HER2 amplification in micrometastatic esophageal cancer cells predicts prognosis. Gastroenterology. 2008; 135:1000-2; discussion 2-3. https://doi.org/10.1053/j.gastro.2008.07.045.

13. Kleespies A, Guba M, Jauch KW, Bruns CJ. Vascular endothelial growth factor in esophageal cancer. J Surg Oncol. 2004; 87:95-104. https://doi.org/10.1002/jso.20070.

14. Sorger PK, Pelham HR. The glucose-regulated protein grp94 is related to heat shock protein hsp90. J Mol Biol. 1987; 194:341-4.

15. Kubota H, Suzuki T, Lu J, Takahashi S, Sugita K, Sekiya $\mathrm{S}$, Suzuki N. Increased expression of GRP94 protein is associated with decreased sensitivity to X-rays in cervical cancer cell lines. Int J Radiat Biol. 2005; 81:701-9. https:// doi.org/10.1080/09553000500434727.

16. Tai CJ, Wang JW, Su HY, Tai CJ, Wang CK, Wu CT, Lien YC, Chang YJ. Glucose-regulated protein 94 modulates the therapeutic efficacy to taxane in cervical cancer cells. Tumour Biol. 2013; 35:403-10. https://doi.org/10.1007/ s13277-013-1056-9.

17. Bando Y, Katayama T, Kasai K, Taniguchi M, Tamatani M, Tohyama M. GRP94 (94 kDa glucose-regulated protein) suppresses ischemic neuronal cell death against ischemia/ reperfusion injury. Eur J Neurosci. 2003; 18:829-40.

18. Wang X, Wang Q, Lin H, Li S, Sun L, Yang Y. HSP72 and gp96 in gastroenterological cancers. Clin Chim Acta. 2013; 417:73-9. https://doi.org/10.1016/j.cca.2012.12.017.

19. Zhang LY, Zhang XC, Wang LD, Zhang ZF, Li PL. Increased expression of GRP94 protein is associated with decreased sensitivity to adriamycin in ovarian carcinoma cell lines. Clin Exp Obstet Gynecol. 2008; 35:257-63.

20. Zheng HC, Takahashi H, Li XH, Hara T, Masuda S, Guan YF, Takano Y. Overexpression of GRP78 and GRP94 are markers for aggressive behavior and poor prognosis in gastric carcinomas. Hum Pathol. 2008; 39:1042-9. https:// doi.org/10.1016/j.humpath.2007.11.009.

21. Pan Z, Erkan M, Streit S, Friess H, Kleeff J. Silencing of GRP94 expression promotes apoptosis in pancreatic cancer cells. Int J Oncol. 2009; 35:823-8.

22. Patel PD, Yan P, Seidler PM, Patel HJ, Sun W, Yang C, Que NS, Taldone T, Finotti P, Stephani RA, Gewirth DT, Chiosis G. Paralog-selective Hsp90 inhibitors define tumor-specific regulation of HER2. Nat Chem Biol. 2013; 9:677-84. https://doi.org/10.1038/nchembio.1335.

23. Chen WT, Tseng CC, Pfaffenbach K, Kanel G, Luo B, Stiles BL, Lee AS. Liver-specific knockout of GRP94 in mice disrupts cell adhesion, activates liver progenitor cells, and accelerates liver tumorigenesis. Hepatology. 2014; 59:94757. https://doi.org/10.1002/hep.26711.

24. Wei PL, Huang CY, Tai CJ, Batzorig U, Cheng WL, Hunag MT, Chang YJ. Glucose-regulated protein 94 mediates metastasis by CCT8 and the JNK pathway in hepatocellular carcinoma. Tumour Biol. 2016; 37:8219-27. https://doi. org/10.1007/s13277-015-4669-3.

25. Huang CY, Batzorig U, Cheng WL, Huang MT, Chen W, Wei PL, Chang YJ. Glucose-regulated protein 94 mediates cancer progression via AKT and eNOS in hepatocellular carcinoma. Tumour Biol. 2016; 37:4295-304. https://doi. org/10.1007/s13277-015-4254-9.

26. Chen $\mathrm{X}$, Ding $\mathrm{Y}$, Liu CG, Mikhail S, Yang CS. Overexpression of glucose-regulated protein 94 (Grp94) in esophageal adenocarcinomas of a rat surgical model and humans. Carcinogenesis. 2002; 23:123-30.

27. Wang $X$, Wang $Q$, Lin $H$. Correlation between clinicopathology and expression of heat shock protein 72 and glycoprotein 96 in human esophageal squamous cell carcinoma. Clin Dev Immunol. 2010; 2010:212537. https:// doi.org/10.1155/2010/212537.

28. Akutsu Y, Matsubara H, Kano M, Usui A, Yoneyama Y, Ikeda N, Komatsu A, Yusup G. Correlation between gp96 expression and the surgical outcome in patients with esophageal squamous cell carcinoma. Ann Surg Oncol. 2011; 18:832-7. https://doi.org/10.1245/s10434-010-1128-7.

29. Wang Q, He Z, Zhang J, Wang Y, Wang T, Tong S, Wang L, Wang S, Chen Y. Overexpression of endoplasmic reticulum molecular chaperone GRP94 and GRP78 in human lung cancer tissues and its significance. Cancer Detect Prev. 2005; 29:544-51. https://doi.org/10.1016/j. cdp.2005.09.010.

30. Neufeld G, Cohen T, Gengrinovitch S, Poltorak Z. Vascular endothelial growth factor (VEGF) and its receptors. FASEB J. 1999; 13:9-22.

31. Kitadai Y, Amioka T, Haruma K, Tanaka S, Yoshihara M, Sumii K, Matsutani N, Yasui W, Chayama K. Clinicopathological significance of vascular endothelial growth factor (VEGF)-C in human esophageal squamous cell carcinomas. Int J Cancer. 2001; 93:662-6. 
32. Mobius C, Freire J, Becker I, Feith M, Brucher BL, Hennig M, Siewert JR, Stein HJ. VEGF-C expression in squamous cell carcinoma and adenocarcinoma of the esophagus. World J Surg. 2007; 31:1768-72; discussion 73-4. https:// doi.org/10.1007/s00268-006-0373-1.

33. Nakagawa S, Kanda T, Kosugi S, Ohashi M, Suzuki T, Hatakeyama K. Recurrence pattern of squamous cell carcinoma of the thoracic esophagus after extended radical esophagectomy with three-field lymphadenectomy. J Am Coll Surg. 2004; 198:205-11. https://doi.org/10.1016/j. jamcollsurg.2003.10.005.

34. Litle VR, Luketich JD, Christie NA, Buenaventura PO, Alvelo-Rivera M, McCaughan JS, Nguyen NT, Fernando HC. Photodynamic therapy as palliation for esophageal cancer: experience in 215 patients. Ann Thorac Surg. 2003; 76:1687-92; discussion 92-3.

35. Cooper JS, Guo MD, Herskovic A, Macdonald JS, Martenson JA Jr, Al-Sarraf M, Byhardt R, Russell AH, Beitler JJ, Spencer S, Asbell SO, Graham MV, Leichman LL. Chemoradiotherapy of locally advanced esophageal cancer: long-term follow-up of a prospective randomized trial (RTOG 85-01). Radiation Therapy Oncology Group. JAMA. 1999; 281:1623-7.

36. Piazuelo E, Jimenez P, Lanas A. COX-2 inhibition in esophagitis, Barrett's esophagus and esophageal cancer. Curr Pharm Des. 2003; 9:2267-80.

37. Gazit G, Lu J, Lee AS. De-regulation of GRP stress protein expression in human breast cancer cell lines. Breast Cancer Res Treat. 1999; 54:135-46.

38. Dong D, Stapleton C, Luo B, Xiong S, Ye W, Zhang Y, Jhaveri N, Zhu G, Ye R, Liu Z, Bruhn KW, Craft N, Groshen S, et al. A critical role for GRP78/BiP in the tumor microenvironment for neovascularization during tumor growth and metastasis. Cancer Res. 2011; 71:2848-57. https://doi.org/10.1158/0008-5472.CAN-10-3151.

39. Li Z, Zhang L, Zhao Y, Li H, Xiao H, Fu R, Zhao C, Wu H, Li Z. Cell-surface GRP78 facilitates colorectal cancer cell migration and invasion. Int J Biochem Cell Biol. 2013; 45:987-94. https://doi.org/10.1016/j.biocel.2013.02.002.

40. Langer R, Feith M, Siewert JR, Wester HJ, Hoefler H. Expression and clinical significance of glucose regulated proteins GRP78 (BiP) and GRP94 (GP96) in human adenocarcinomas of the esophagus. BMC Cancer. 2008; 8:70. https://doi.org/10.1186/1471-2407-8-70.

41. Shirvani VN, Ouatu-Lascar R, Kaur BS, Omary MB, Triadafilopoulos G. Cyclooxygenase 2 expression in Barrett's esophagus and adenocarcinoma: Ex vivo induction by bile salts and acid exposure. Gastroenterology. 2000; 118:487-96.

42. Shamma A, Yamamoto H, Doki Y, Okami J, Kondo M, Fujiwara Y, Yano M, Inoue M, Matsuura N, Shiozaki $\mathrm{H}$, Monden M. Up-regulation of cyclooxygenase-2 in squamous carcinogenesis of the esophagus. Clin Cancer Res. 2000; 6:1229-38.
43. Hida T, Yatabe $Y$, Achiwa H, Muramatsu H, Kozaki K, Nakamura S, Ogawa M, Mitsudomi T, Sugiura T, Takahashi T. Increased expression of cyclooxygenase 2 occurs frequently in human lung cancers, specifically in adenocarcinomas. Cancer Res. 1998; 58:3761-4.

44. Tsujii M, Kawano S, Tsuji S, Sawaoka H, Hori M, DuBois $\mathrm{RN}$. Cyclooxygenase regulates angiogenesis induced by colon cancer cells. Cell. 1998; 93:705-16.

45. Tsujii M, Kawano S, DuBois RN. Cyclooxygenase-2 expression in human colon cancer cells increases metastatic potential. Proc Natl Acad Sci U S A. 1997; 94:3336-40.

46. Dohadwala M, Batra RK, Luo J, Lin Y, Krysan K, Pold M, Sharma S, Dubinett SM. Autocrine/paracrine prostaglandin E2 production by non-small cell lung cancer cells regulates matrix metalloproteinase- 2 and CD44 in cyclooxygenase2-dependent invasion. J Biol Chem. 2002; 277:50828-33. https://doi.org/10.1074/jbc.M210707200.

47. Sui H, Zhou S, Wang Y, Liu X, Zhou L, Yin P, Fan Z, Li Q. COX-2 contributes to P-glycoprotein-mediated multidrug resistance via phosphorylation of c-Jun at Ser63/73 in colorectal cancer. Carcinogenesis. 2011; 32:667-75. https:// doi.org/10.1093/carcin/bgr016.

48. Zimmermann KC, Sarbia M, Weber AA, Borchard F, Gabbert HE, Schror K. Cyclooxygenase-2 expression in human esophageal carcinoma. Cancer Res. 1999; 59:198-204.

49. Funkhouser EM, Sharp GB. Aspirin and reduced risk of esophageal carcinoma. Cancer. 1995; 76:1116-9.

50. Chen WS, Wei SJ, Liu JM, Hsiao M, Kou-Lin J, Yang WK. Tumor invasiveness and liver metastasis of colon cancer cells correlated with cyclooxygenase-2 (COX-2) expression and inhibited by a COX-2-selective inhibitor, etodolac. Int $\mathrm{J}$ Cancer. 2001; 91:894-9.

51. Fantappie O, Solazzo M, Lasagna N, Platini F, Tessitore L, Mazzanti R. P-glycoprotein mediates celecoxib-induced apoptosis in multiple drug-resistant cell lines. Cancer Res. 2007; 67:4915-23. https://doi.org/10.1158/0008-5472.CAN-06-3952.

52. Ito K, Suda T. Metabolic requirements for the maintenance of self-renewing stem cells. Nat Rev Mol Cell Biol. 2014; 15:243-56. https://doi.org/10.1038/nrm3772.

53. Tan AS, Baty JW, Dong LF, Bezawork-Geleta A, Endaya B, Goodwin J, Bajzikova M, Kovarova J, Peterka M, Yan B, Pesdar EA, Sobol M, Filimonenko A, et al. Mitochondrial genome acquisition restores respiratory function and tumorigenic potential of cancer cells without mitochondrial DNA. Cell Metab. 2015; 21:81-94. https:// doi.org/10.1016/j.cmet.2014.12.003.

54. Vander Heiden MG, Cantley LC, Thompson CB. Understanding the Warburg effect: the metabolic requirements of cell proliferation. Science. 2009; 324:102933. https://doi.org/10.1126/science.1160809.

55. Krisher RL, Prather RS. A role for the Warburg effect in preimplantation embryo development: metabolic modification to support rapid cell proliferation. Mol Reprod Dev. 2012; 79:311-20. https://doi.org/10.1002/mrd.22037. 
56. Marzec M, Eletto D, Argon Y. GRP94: An HSP90like protein specialized for protein folding and quality control in the endoplasmic reticulum. Biochim Biophys Acta. 2012; 1823:774-87. https://doi.org/10.1016/j. bbamcr.2011.10.013.

57. Wang XY, Subjeck JR. High molecular weight stress proteins: Identification, cloning and utilisation in cancer immunotherapy. Int J Hyperthermia. 2013; 29:364-75. https://doi.org/10.3109/02656736.2013.803607.

58. Ni M, Lee AS. ER chaperones in mammalian development and human diseases. FEBS Lett. 2007; 581:3641-51. https://doi.org/10.1016/j.febslet.2007.04.045.

59. Giorgi C, De Stefani D, Bononi A, Rizzuto R, Pinton P. Structural and functional link between the mitochondrial network and the endoplasmic reticulum. International Journal of Biochemistry \& Cell Biology. 2009; 41:1817-27. https://doi.org/10.1016/j.biocel.2009.04.010.

60. Fu Y, Li J, Lee AS. GRP78/BiP inhibits endoplasmic reticulum BIK and protects human breast cancer cells against estrogen starvation-induced apoptosis. Cancer Res. 2007; 67:3734-40. https://doi.org/10.1158/0008-5472. CAN-06-4594.

61. Dejeans N, Glorieux C, Guenin S, Beck R, Sid B, Rousseau R, Bisig B, Delvenne P, Buc Calderon P, Verrax J. Overexpression of GRP94 in breast cancer cells resistant to oxidative stress promotes high levels of cancer cell proliferation and migration: implications for tumor recurrence. Free Radic Biol Med. 2012; 52:993-1002. https://doi.org/10.1016/j.freeradbiomed.2011.12.019.

62. Okines A, Cunningham D, Chau I. Targeting the human EGFR family in esophagogastric cancer. Nat Rev Clin Oncol. 2011; 8:492-503. https://doi.org/10.1038/ nrclinonc.2011.45.
63. Somanath PR, Razorenova OV, Chen J, Byzova TV. Akt1 in endothelial cell and angiogenesis. Cell Cycle. 2006; 5:512-8.

64. Basso AD, Solit DB, Chiosis G, Giri B, Tsichlis P, Rosen N. Akt forms an intracellular complex with heat shock protein 90 (Hsp90) and Cdc37 and is destabilized by inhibitors of Hsp90 function. J Biol Chem. 2002; 277:39858-66. https:// doi.org/10.1074/jbc.M206322200.

65. Chiou JF, Tai CJ, Huang MT, Wei PL, Wang YH, An J, Wu $\mathrm{CH}$, Liu TZ, Chang YJ. Glucose-regulated protein 78 is a novel contributor to acquisition of resistance to sorafenib in hepatocellular carcinoma. Ann Surg Oncol. 2010; 17:60312. https://doi.org/10.1245/s10434-009-0718-8.

66. Chang YJ, Chiu CC, Wu CH, An J, Wu CC, Liu TZ, Wei PL, Huang MT. Glucose-regulated protein 78 (GRP78) silencing enhances cell migration but does not influence cell proliferation in hepatocellular carcinoma. Ann Surg Oncol. 2010; 17:1703-9. https://doi.org/10.1245/s10434010-0912-8.

67. Hirsch FR, Varella-Garcia M, Bunn PA Jr, Di Maria MV, Veve R, Bremmes RM, Baron AE, Zeng C, Franklin WA. Epidermal growth factor receptor in non-smallcell lung carcinomas: correlation between gene copy number and protein expression and impact on prognosis. J Clin Oncol. 2003; 21:3798-807. https://doi.org/10.1200/ JCO.2003.11.069.

68. Wei PL, Kuo LJ, Wang W, Lin FY, Liu HH, How T, Ho YS, Huang MT, Wu CH, Chang YJ. Silencing of glucoseregulated protein 78 (GRP78) enhances cell migration through the upregulation of vimentin in hepatocellular carcinoma cells. Ann Surg Oncol. 2012; 19:S572-9. https:// doi.org/10.1245/s10434-011-2055-y. 